JGG 2022:70:17-24

doi: $10.36150 / 2499-6564-N 359$

\title{
Evaluation of the relationship between lower urinary tract symptoms and fall risks in male patients over 65 years old
}

\author{
Saliha Buşra Aksu¹, Güzin Zeren Öztürk², Memet Taşkın Egici', \\ Cüneyt Ardıç ${ }^{4}$ \\ ${ }^{1}$ Family Medicine, Aslanapa District State Hospital, Aslanapa/Kütahya, Turkey; ${ }^{2}$ Family Medicine, Health \\ Science University Şişli Hamidiye Etfal Training and Research Hospital Şişli/İstanbul, Turkey; ${ }^{3}$ Family \\ Medicine, Health Science University Haydarpaşa Numune Training and Research Hospital Kadıköy/ \\ İstanbul, Turkey; ${ }^{4}$ Family Medicine, Recep Tayyip Erdoğan University Medicine Faculty Rize/Turkey
}

Received: February 19, 2021

Accepted: August 18, 2021

\section{Correspondence \\ Saliha Büşra Aksu \\ Hürriyet Mahallesi, Kara Sokak 16, 43210 \\ Aslanapa District State Hospital \\ Aslanapa/Kütahya/Turkey \\ E-mail: drsalihabusra@gmail.com}

How to cite this article: Aksu SB, Öztürk GZ, Egici MT, et al. Evaluation of the relationship between lower urinary tract symptoms and fall risks in male patients over 65 years old. Journal of Gerontology and Geriatrics 2022;70:17-24. https://doi. org/10.36150/2499-6564-N359

(C) Copyright by Società Italiana

di Gerontologia e Geriatria (SIGG)

\section{(c) (1) $(9)$}

This is an open access article distributed in accordance with the CC-BY-NC-ND (Creative Commons Attribution-NonCommercial-NoDerivatives 4.0 International) license. The article can be used by giving appropriate credit and mentioning the license, but only for non-commercial purposes and only in the original version. For further information: https://creativecommons.org/licenses/by-nc-nd/4.0/deed.en
Objective. In our study, we aimed to evaluate the relationship between LUTS and fall risk in patients over 65 years old.

Methods. 183 people over 65 years old who attended to Health Sciences University Şişli Hamidiye Etfal Training and Research Hospital Family Medicine Polyclinics and Recep Tayyip Erdoğan University Family Medicine Polyclinics between February 2017-May 2017 were included in the study and 'Individual Presentation Form' prepared by the researcher questioning socio-demographic characteristics was applied to the participants by face-to-face questioning method, International Prostate Symptom Score (IPSS) and Morse Fall Scale (MFS) were completed afterwards and ROC analysis of IPSS was performed for those who have high risk in terms of MFS.

Results. When evaluating the relationship between MFS and IPSS, we observed that as all subscores and total score of IPSS increased, the MFS score increased. The MFS scores of the participants whose IPSS classification was evaluated as severe were found to be significantly higher. ROC analysis of IPSS was performed for those who have high risk in terms of MFS. It was found that area under curve is $78.4 \%$, and those with an IPSS of 13.5 and above show a high fall risk with $71.4 \%$ sensitivity and $70 \%$ specificity.

Conclusions. In our study, we found that as the IPSS of the participants increased, the risk of falling increased. Moreover, we found that age, occupation type, type and number of chronic diseases were effective in both fall and IPSS. In addition to LUTS screening in males, evaluation should be done for the risk of falling.

Key words: prostate, accidental falls, elderly

\section{INTRODUCTION}

According to World Health Organization $(\mathrm{WHO})$, the falling rate of individuals aged 65 and over is $28.0-35.0 \%$ every year, while this rate increases to $32.0-42.0 \%$ after the age of $70{ }^{1}$. In addition to the increase in certain diseases in older ages, there is a decrease in physical abilities and an increase in the risk of accidents as well. The tendency to fall increases due to various reasons, especially decrease in physical and cognitive abilities, loss of muscle strength, drug use and vision problems, and it is 
reported that at least $50 \%$ of individuals over the age of 65 experience falls once a year. While some of the falls caused non-fatal injuries such as increased use of healthcare providers, decreased function and loss of independence; 10 to $20 \%$ result in serious injuries such as fractures or head injuries ${ }^{2-5}$.

With respect to the 2017 statistics of the USA Centers for Disease Control and Prevention, 2.8 million people apply to the emergency department annually due to falls, more than 800.000 are hospitalized and more than 27.000 die in the end. While the total annual cost of injuries due to falls in 2015 was approximately 50 billion dollars, the amount is currently approaching 70 billion dollars ${ }^{6}$. Determining the risks for falling and taking precautions are among the best protection methods. A meta-analysis ${ }^{7}$ showed that fall prevention programs reduced the risk of falls by $11 \%$, while a systematic review 8 showed that multidimensional interventions reduced the risk of falls by $27 \%$ in the elderly living in the community.

Lower urinary tract symptoms (LUTS) are the subjective indicator of a disease or change that affects bladder and the urethra as perceived by the patient, caregiver or partner and traditionally classified into storage, voiding and post micturition symptoms ${ }^{9}$. LUTS is seen in $15-60 \%$ of men over the age of 40 , and its incidence increases rapidly with age ${ }^{10}$. Sypmtoms as increase in the frequency of urination(need to urinate more than 8 per day), nocturia (need to urinate at night), urgency (sudden and non-delayed urination), urinary incontinence not only negatively affect the quality of life, but also may cause accidents and falls ${ }^{11,12}$.

Recent studies have shown that Bening prostate obstruction-related parameters (prostate volume, postvoid residual, peak flow rate) have an inverse relationship with prostate cancer $(\mathrm{PCa})$, The addition of parameters like age and PSA significantly increases the models' accuracy in predicting $\mathrm{PCa}{ }^{13}$. Simirlarly, when patients diagnosed with prostate cancer were compared with patients diagnosed with $\mathrm{BPH}$; a study found that age and PSa values to be higher and IPSS values to be lower in PCa group ${ }^{14}$. Nevertheless Falagario et al. found age as the most important predictor in the diagnosis of $\mathrm{PCa}$ in their study, especially in those with a PSA value of up to $10 \mathrm{ng} / \mathrm{ml}$, this risk was found to be 5 times higher than in younger counterparts ${ }^{15}$. Therefore, the final clinical decision has to rely on wise clinical judgment.

In our study, we aimed to evaluate the relationship between LUTS and fall risk in patients over 65 years old.

\section{MATERIALS AND METHODS}

The population of this descriptive prospective study composed of men over 65 years old who had been admitted to Health Sciences University Şişli Hamidiye Etfal Training and Research Hospital Family Medicine Polyclinics and Recep Tayyip Erdoğan University Family Medicine Polyclinics for any reason and agreed to participate in the study between February 2017-April 2017. The number of male patients aged 65 and over who applied to both outpatient clinics in the last three months was 350. The sample size was calculated with 95\% confidence over this attendence number and was determined as 183. In this 3-month period, we aimed to carry out our study with 183 patients who met the appropriate criteria. Men at the age of 65 and over who agreed to participate in the study were included in the study. Patients with a history of previous urological operation, a history of prostate cancer, a history of urinary incontinence or previously treated for this reason were not included in the study.

'Individual Presentation Form' prepared by the researcher questioning socio-demographic characteristics (age, occupation, education level, monthly income, history of previous diseases) was applied to the participants by face-to-face questioning method, and the International Prostate Symptom Score (IPSS) and Morse Fall Scale (MFS) were completed afterwards. Information of 200 patients was obtained, but 17 of them were not included in the study because they did not have the appropriate criteria.

\section{International Prostate Symptom Score}

The International Prostate Symptom Score consists of 8 questions, 7 questions regarding the symptoms associated with benign prostatic hyperplasia and 1 question for the quality of life. The version developed by the American Urological Association in 1992 did not contain the question of quality of life and was named the American Urological Association Symptom Score (AUA-7), later it was named IPSS after the World Health Organization added the eighth question.

Questions 2, 4 and 7 in the IPSS form question storage symptoms, while questions 1, 3, 5 and 6 ask about voiding symptoms. Symptom score total score can range from 0 to 35 (excluding quality of life). In clinical use, the symptom level is divided into three groups; mild for 0-7 points, moderate for 8-19 points and severe for 20-35 points ${ }^{16,17}$.

\section{Morse Fall Scale}

Morse Fall Scale was developed by Janice M. Morse in 1985. The MFS consists of six items (a history of falling in the past three months, secondary diagnosis, ambulatory aids, intravenous therapy, gait, and mental status) with mutually different scores, which are attributed to each patient and can range between 0 and 125 points. 
Patients classified between 0 and 24 points are at low risk of falls during the hospitalization; patients classified between 25 and 44 points are at moderate risk of falls; and patients with 45 points or more are at high risk of falls. At the cut-off score of 45 , sensitivity was established at a value of $78 \%$, specificity was established at a value of $83 \%{ }^{18}$.

Ethics committee approval for the study was given by the Recep Tayyip Erdogan University Clinical Research Ethics Committee and was obtained with the 2018/61 protocol of the relevant committee dated 30.03.2018. The IBM SPSS version 20 (Statistical Package for the Social Sciences) program was used for statistical analysis and $p<0.05$ was considered significant. The socio-demographic data obtained were evaluated with their number and percentage dispersions. Descriptive statistics are shown as mean \pm standard deviation for continuous and discrete numerical variables, and categorical variables as the number of cases and (\%). Categorical variables were analyzed using Pearson's Chi-Square test. Whether there is a statistically significant relationship between continuous and discrete numeric variables was investigated using Spearman's Correlation test.

\section{RESULTS}

The sociodemographic characteristics of the men in the study were evaluated and are shown in Table I. A total of 183 men participated in the study; the average age was $71.47 \pm 6.04$ ( $\min : 65$, max: 88 ).

The IPSS mean of the participants were $10.38 \pm 8.09$. In clinical use, the International Prostate Symptom Score levels are divided into three groups; 0-7 points mild, 8-19 points moderate, 20-35 points severe, In Figure 1, the distribution of the participants according to the groups was given and most of them had mild symptoms $(48.1 \% ; n=88)$.
Table I. Sociodemographic characteristics.

\begin{tabular}{|c|c|c|c|}
\hline \multicolumn{2}{|c|}{} & N & $\%$ \\
\hline \multirow{2}{*}{ Age groups } & $65-74$ & 127 & 69,4 \\
\cline { 2 - 4 } & $75-84$ & 50 & 27.3 \\
\cline { 2 - 4 } & $\geq 85$ & 6 & 3.3 \\
\hline \multirow{2}{*}{ Education level } & Illiterate & 19 & 10.4 \\
\cline { 2 - 4 } & Below High School & 125 & 68.3 \\
\cline { 2 - 4 } & $\begin{array}{c}\text { High School and } \\
\text { above }\end{array}$ & 39 & 21.3 \\
\hline \multirow{2}{*}{ Occupation } & Blue-collar & 122 & 66.7 \\
\cline { 2 - 4 } & White-collar & 61 & 33.3 \\
\hline Secondery diagnosis & Yes & 135 & 73.8 \\
\cline { 2 - 4 } & No & 48 & 26.2 \\
\hline
\end{tabular}

The MFS mean of the participants were $13.57 \pm 14.65$. According to the Morse Fall Scale, patients are evaluated in the low risk group if they score between 0-24 points, in the medium risk group if they score between 25-50 points, and in the high risk group if they score 51 points or more. In Figure 2, the distribution of the participants according to their MFS scores was given. $86.9 \%(n=159)$ of the participants were found to be at low risk group.

The relationship between the sociodemographic characteristics, MFS scores and IPSS of the participants were given in Table II. While there was a significant relationship between MFS, age and having a blue-collar job (p: 0.039, p: 0.000 respectively), a significant relationship was found only between IPSS and having a blue-collar job. (p: 0.009)

The most common disease among the participants was hypertension (HT) with 63.9\% (n: 117) and it was followed by diabetes mellitus (DM) (26.2\%, n: 48). The relationship between the chronic diseases of the participants, MFS scores and IPSS were given in Table III. Considering the relationship between the number of chronic diseases and the scores, the MFS and IPSS of the participants with 3

Table II. The relationship between the sociodemographic characteristics, MFS scores and IPSS of the participants.

\begin{tabular}{|c|c|c|c|c|c|c|c|}
\hline & & $\begin{array}{c}\text { Morse Fall Scale } \\
\text { Score }\end{array}$ & $\mathbf{P}$ & $\mathbf{R}$ & IPSS total & $\mathbf{P}$ & $\mathbf{R}$ \\
\hline & & Mean Rank & & & Mean Rank & & \\
\hline \multirow{2}{*}{\multicolumn{2}{|c|}{$\mathrm{Age}^{\star}$}} & 13.57 & 0.039 & 0.152 & 10.38 & 0.141 & 0.109 \\
\hline & & $\begin{array}{l}\text { Mean } \pm \text { std. } \\
\text { deviation }\end{array}$ & \multicolumn{2}{|c|}{$\mathbf{P}$} & $\begin{array}{l}\text { Mean } \pm \text { std. } \\
\text { deviation }\end{array}$ & \multicolumn{2}{|c|}{$\mathbf{P}$} \\
\hline \multirow[t]{3}{*}{ Education Level $^{* *}$} & Illiterate & $20.00 \pm 18.78$ & \multirow{3}{*}{\multicolumn{2}{|c|}{0.193}} & $14.84 \pm 8.15$ & \multirow{3}{*}{\multicolumn{2}{|c|}{0.053}} \\
\hline & Below High School & $13.98 \pm 15.35$ & & & $9.81 \pm 7.53$ & & \\
\hline & High School and above & $9.15 \pm 7.12$ & & & $10.05 \pm 9.25$ & & \\
\hline \multirow[t]{2}{*}{ Occupation } & Blue-collar & $16.47 \pm 16.35$ & \multirow{2}{*}{\multicolumn{2}{|c|}{0.000}} & $11.36 \pm 7.92$ & \multirow{2}{*}{\multicolumn{2}{|c|}{0.009}} \\
\hline & White-collar & $7.78 \pm 7.79$ & & & $8.44 \pm 8.14$ & & \\
\hline
\end{tabular}

\footnotetext{
*Spearman's Correlation Test; "'Chi-square test
} 


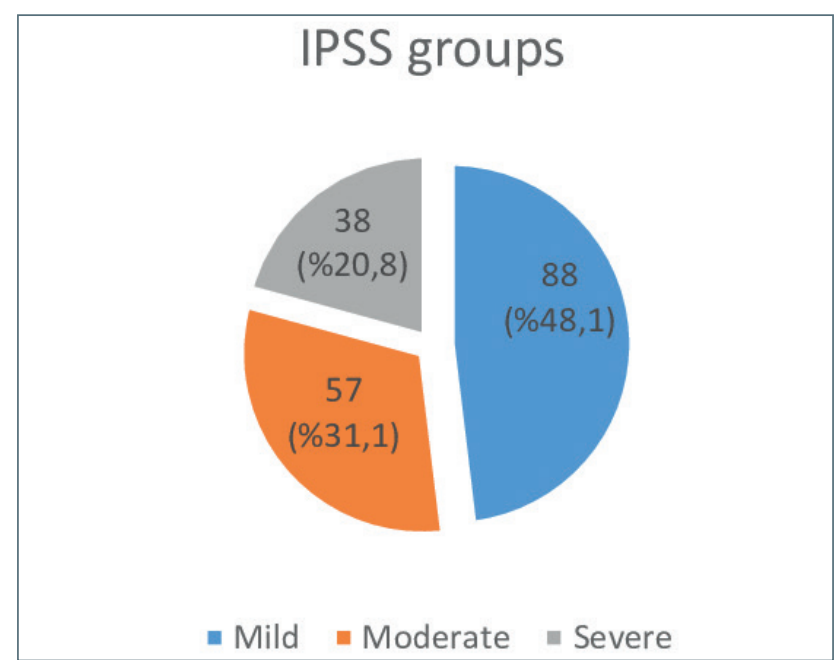

Figure 1. Distribution of the participants according to IPSS.

or more chronic diseases were found to be significantly higher. (p: 0.000 and p: 0.002, respectively)

The number of patients using diuretics was 71 (38.3\%), and the number of patients using antidiabetics was 48 (26.2\%). A significant relationship was found between the use of diuretics, anti-diabetics, MFS and IPSS. (p: $0.001, p: 0.000, p: 0.001$ ve p: 0.000 respectively) The patients using diuretic and antidiabetic drugs were found to have significantly higher MFS and IPSS.

The mean PSA of the participants was $3.11 \pm 4.30$, and the PSA values of 40 (25.8\%) participants were above the normal limit. While there was no significant difference between the PSA scores and age (p: 0.932, r: 0.007), a significant correlation was found between PSA and

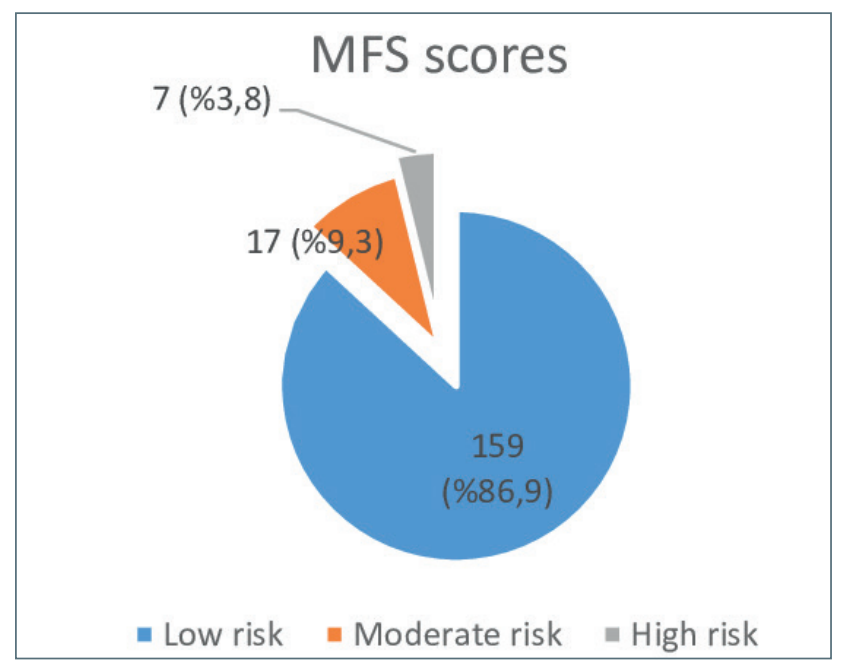

Figure 2. Distribution of the participants according to MFS.

IPSS, it was as the IPSS increased, the PSA increased. (p: 0.000, r: 0.317) There was no significant relationship betweenPSAscoresandMFSscores. (p: 0.305, r: 0.083). When evaluating the relationship between MFS and IPSS (Tab. IV); we observed that as all subscores and total score of IPSS increased, the MFS score increased. The MFS scores of the participants whose IPSS classification was evaluated as severe were found to be significantly higher. (p: 0.000) (Tab. V).

ROC analysis of IPSS was performed for those who have high risk in terms of MFS. It was found that area under curve is $78.4 \%$, and those with an IPSS of 13.5 and above show a high fall risk with $71.4 \%$ sensitivity and $70 \%$ specificity.

Table III. The relationship between the chronic diseases of the participants, MFS scores and IPSS.

\begin{tabular}{|c|c|c|c|c|c|c|}
\hline & & \multirow[t]{2}{*}{$\mathbf{N}$} & Morse Fall Scale Score & \multirow[t]{2}{*}{$\mathbf{P}$} & IPSS total & \multirow[t]{2}{*}{$\mathbf{P}$} \\
\hline & & & Median (IQR) & & Median (IQR) & \\
\hline \multirow[t]{2}{*}{ Hypertension* } & Yes & 117 & $15.00(15.00-15.00)$ & \multirow[t]{2}{*}{0.000} & $8.00(5.00-20.00)$ & \multirow[t]{2}{*}{0.013} \\
\hline & No & 66 & $0.00(0.00-15.00)$ & & $6.00(2.00-14.00)$ & \\
\hline \multirow[t]{2}{*}{$\mathrm{DM}^{*}$} & Yes & 48 & $15.00(15.00-27.50)$ & \multirow[t]{2}{*}{0.000} & $10.00(5.00-23.00)$ & \multirow[t]{2}{*}{0.004} \\
\hline & No & 135 & $15.00(0.00-15.00)$ & & $7.00(4.00-14.00)$ & \\
\hline \multirow[t]{2}{*}{ Chronic lung disease $^{\star}$} & Yes & 32 & $15.00(15.00-15.00)$ & \multirow[t]{2}{*}{0.046} & $10.50(4.50-19.00)$ & \multirow[t]{2}{*}{0.438} \\
\hline & No & 151 & $15.00(0.00-15.00)$ & & $8.00(5.00-17.00)$ & \\
\hline \multirow[t]{2}{*}{ Chronic heart disease* } & Yes & 18 & $15.00(15.00-28.75)$ & \multirow[t]{2}{*}{0.003} & $15.00(4.50-23.25)$ & \multirow[t]{2}{*}{0.149} \\
\hline & No & 165 & $15.00(0.00-15.00)$ & & $8.00(4.50-16.00)$ & \\
\hline \multirow[t]{2}{*}{ Thyroid disease* } & Yes & 13 & $15.00(15.00-47.50)$ & \multirow[t]{2}{*}{0.001} & $18.00(5.50-22.00)$ & \multirow[t]{2}{*}{0.041} \\
\hline & No & 170 & $15.00(0.00-15.00)$ & & $8.00(4.00-16.00)$ & \\
\hline \multirow{4}{*}{$\begin{array}{c}\text { Number of chronic } \\
\text { diseases }\end{array}$} & None & 49 & $0.00(0.00-0.00)$ & \multirow[t]{4}{*}{0.000} & $6.00(2.00-13.50)$ & \multirow[t]{4}{*}{0.002} \\
\hline & 1 & 46 & $15.00(1.50-15.00)$ & & $8.00(4.75-10.00)$ & \\
\hline & 2 & 42 & $15.00(15.00-15.00)$ & & $8.50(4.75-20.00)$ & \\
\hline & 3 or more & 46 & $15.00(15.00-32.50)$ & & $16.00(5.00-23.00)$ & \\
\hline
\end{tabular}

*Mann-Whithey U Test; **Kruskal Wallis Test 


\section{DISCUSSION}

Falls are not generally due to a single cause, but occur as a result of the effect of preparatory and accelerating factors. Although it is difficult to try to correct all the underlying causes, a properly structured intervention can reduce the frequency of falls. The American Geriatric Association recommends that primary healthcare providers evaluate all older adults at least once a year for falls, frequency of falls, gait and balance disturbances ${ }^{19}$. In our study, we found that the risk of falling increases with increasing age, in accordance with the literature ${ }^{20}$. The main problem that falls cause in the elderly is that the injuries are more severe and the recovery is longer ${ }^{21}$. Although there are no compatible studies in the literature, we found that the MFS scores of the participants who worked as blue-collar before were significantly higher than those who worked as white-collar. We think that the reason for this may be related to the fact that people who worked with body strength rather than desk jobs have more staleness.

Evaluating the relationship between chronic diseases and MFS, we found that those with 3 or more chronic diseases had significantly higher MDI scores. The relationship between the number of chronic diseases and the risk of falling was found similarly in a study conducted in Canada ${ }^{22}$. When the diseases were examined separately; patients with HT, DM, CLD, heart diseases and thyroid diseases had a significantly higher MFS score. Results are consistent with the literature ${ }^{23,24}$.

It is known that both the hypertension disease itself and the treatments given cause orthostotic hypotension 25,26 and it has been shown that people with orthostaic hypotension and uncontrolled HT have 2.5 times the risk of falling compared to those who do not ${ }^{27}$. According to the list published by The National Board of Health and Welfare (NBHW) in Switzerland, diuretics are on the list of drugs that can cause orthostatic hypotension, so they may increase the risk of falls ${ }^{28}$. In our study, we found that patients using diuretics had higher MFS scores.

Having diabetes has previously been associated with risk of falling. Krauss et al. found a significant relationship between the use of antidiabetic drugs and the risk of falling ${ }^{29}$. In our study, we found a relationship between DM, antidiabetic drug use and MFS scores. One of the potential reasons for this may be that diabetes medications cause hypoglycemia to cause falls, or may be the consequences of diabetes complications such as peripheral neuropathy or polyuria ${ }^{30}$.

Similar to our study; Recent studies have shown that the risk of falling is increased in patients with COPD. Although the exact mechanism is unknown, skeletal muscle dysfunction and cerebal hypoxemia are blamed factors ${ }^{31,32}$.
Table IV. Evaluation of the relationship between the participants' MFS scores and IPSS.

\begin{tabular}{|c|c|c|}
\hline & \multicolumn{2}{|c|}{ Morse Fall Scale Scores } \\
\hline & P-value & R-value \\
\hline IPSS 1 (incomplete emptying) & 0.000 & $0.293^{\star \star}$ \\
\hline IPSS 2 (frequency) & 0.016 & $0.177^{\star}$ \\
\hline IPSS 3 (intermittency) & 0.008 & $0.194^{\star}$ \\
\hline IPSS 4 (urgency) & 0.000 & $0.410^{\star \star}$ \\
\hline IPSS 5 (weak stream) & 0.001 & $0.249^{\star \star}$ \\
\hline IPSS 6 (straining to void) & 0.001 & $0.236^{\star \star}$ \\
\hline IPSS 7 (nocturia) & 0.006 & $0.203^{\star \star}$ \\
\hline IPSS total & 0.000 & $0.333^{\star \star}$ \\
\hline
\end{tabular}

Table V. Comparison of IPSS Classification and MFS Scores.

\begin{tabular}{|c|c|c|c|c|}
\hline \multicolumn{2}{|c|}{} & \multicolumn{3}{|c|}{ Morse Fall Scale Score } \\
\cline { 2 - 5 } \multicolumn{2}{|c|}{} & N & Median (IQR) & P \\
\hline \multirow{2}{*}{$\begin{array}{c}\text { IPSS } \\
\text { classification }\end{array}$} & Mild & 88 & $15.00(0.00-15.00)$ & 0.000 \\
\cline { 2 - 4 } & Moderate & 57 & $15.00(0.00-15.00)$ & \\
\cline { 2 - 4 } & Severe & 38 & $15.00(15.00-21.25)$ & \\
\hline
\end{tabular}

In a study conducted with 5015 participants in Brazil, similar to our study, an increase in the IPSS was found as the age increases ${ }^{33}$. In our study, a relationship was found between IPSS and working as a blue collar and having DM, HT, and TD. It is known that diabetes mellitus causes defects in bladder emptying and urgency ${ }^{34}$. For this reason, it is expected that IPSS of DM patients are significantly higher.

The mean PSA of the participants was $3.11 \pm 4.30$, considering the age of the participants, the reason for the Iow PSA values may be because we included urologically healthy individuals in the study and excluded those with a history of prostate CA and operation. Looking at the studies evaluating the relationship between PSA and IPSS; Favilla et al. ${ }^{35}$ and Tsukamoto et al. ${ }^{36}$ did not find a significant correlation between PSA and IPSS in their studies, while Soo Park et al. ${ }^{37}$ found a significant correlation between PSA and IPSS similar to our study. In the literature, there are studies showing that LUTS is a factor that increases the risk of falls in the elderly, especially nocturia and urinary incontinence increase the possibility of falls ${ }^{38,39}$. In a descriptive study conducted in a geriatric hospital, it was found that most of the falls occurred between the patient's room and the toilet or in the toilet itself ${ }^{40}$. Between 20 and $50 \%$ of falls in institutions have been associated with toilet facilities ${ }^{40}$. In a population-based study conducted with 658 people, a significant relationship was found between increased voiding frequency and hip fracture ${ }^{41}$. Again, Parsons et al. found that the frequency 
of urination increased the risk of falling ${ }^{42}$. Chiarelli et al. showed that lower urinary tract symptoms such as incontinence, urgency and nocturia can be associated with falls. ${ }^{43}$ In a cross-sectional study, the risk of falling was found to be significantly higher in patients with nocturia at least twice a night ${ }^{39}$. In our study a significant relationship was found between all sub scores and total score of IPSS and MFS scores. Studies and results show that a common urological disorder causes a non-urological morbidity. Although LUTS seen in the elderly is considered as a natural consequence of aging and a relatively harmless condition, studies prove that there are strong links between urinary health and physical health. Considering the frequency of LUTS and the consequences that may occur with falls, healthcare professionals should question all patients in the risky group in terms of urinary symptoms. In our study, the risk of falling was found to be high in patients with an IPSS of 13.5 and above, with a sensitivity of $72 \%$. When assessing fall risk, clinicians' use of a form that questions urinary symptoms, such as the IPSS, may increase predictability. With appropriate treatment, urinary symptoms should be relieved. In the management of male LUTS, it is equally important to treat the prostate and also bladder and urethra to increase the chances of treatment success so that morbidity could be avoided ${ }^{44}$.

Our study has limitations. It is known that urinary incontinence is also a factor that increases falls, but we did not include patients with urinary incontinence in the study. We also evaluated patients only at their first outpatient visit, and did not reassess their condition after treatment or recommendations.

\section{CONCLUSIONS}

In our study, we found that as the IPSS of the participants increased, the risk of falling increased. In addition, we found that age, occupation type, type and number of chronic diseases were effective in both fall and IPSS.

In addition to LUTS screening in males, we think that evaluation should be done for the risk of falling.

\section{Ethical consideration}

Ethics committee approval for the study was given by the Recep Tayyip Erdogan University Clinical Research Ethics Committee and was obtained with the 2018/61 protocol of the relevant committee dated 30.03.2018.

\section{Acknowledgement}

We would like to express our gratitude to all individuals who agreed to participate in our study.

\section{Funding}

The authors received no financial support for the research, authorship, and/or publication of this article.

\section{Conflict of interest}

The authors declared no potential conflicts of interest with respect to the research, authorship, and/or publication of this article.

\section{References}

1 World Health Organization. WHO global report on falls prevention in older age, 2007;1-48 (http://www.who.int/ageing/publications/Falls_prevention7March.pdf Accessed on: 12/14/2020).

2 Yıldırım YK, Karadakovan A. Yaşlı bireylerde düşme korkusu, günlük yaşam aktiviteleri ve yaşam kalitesi arasındaki ilişki. Türk Geriatri Derg 2004;7:78-83.

3 İlçe AÖ, İlçe AC, Dıramalı A. Yaşlıarda ev kazalarının önlenmesi ve ev kazalarının önlenmesine yönelik iç mekan çözümlemeleri. Hacettepe Üniv. Sosyolojik Araştırmalar e- dergisi 2007;1:1-13.

4 Barnett D. Factors associated with falls in community dwelling individuals age 90 years or older. A Thesis presented to the Department of Social Work California State University, Los Angeles, 2003.

5 Dunne TJ, Gaboury I, Ashe MC. Falls in hospital increase length of stay regardless of degree of harm. J Eval Clin Pract 2014;20:396-400.

6 National Council on Aging. Fall free Initiative (https://www. ncoa.org/healthy-aging/falls-prevention /falls-freeinitiative/ Accessed on: 17.02.2020).

7 Rand Corporation, Southern California Evidence-Based Practice Center. (2003). Evidence report and evidencebased recommendations: fall prevention interventions in the Medicare population (Contract number 500-98-0281). Santa Monica, CA.

8 Gillespie LD, Robertson MC, Gillespie WJ, et al. Interventions for preventing falls in older people living in the community. Cochrane Database System Rev 2009;2:CD007146. https//doi.org/10.1002/14651858.CD007146.pub2

9 Abrams P, Cardozo L, Fall M, et al. Standardisation SubCommittee of the International Continence Society. The standardisation of terminology in lower urinary tract function: report from the standardisation sub-committee of the International Continence Society. Urology 2003;61:37-49. https://doi.org/10.1016/s0090-4295(02)02243-4

10 Wei JT, Calhoun E, Jacobsen SJ. Urologic diseases in America project: benign prostatic hyperplasia. J Urol 2005;173:1256-1261

11 Decalf V, Bower W, Rose G, et al. Prevalence and characteristics of incident falls related to nocturnal toileting in hospitalized patients. Acta Clin Belg 2019:1-6. https://doi. org/10.1080/17843286.2019.1660022 
12 Rose G, Decalf V, Everaert K, et al. Toileting-related falls at night in hospitalised patients: the role of nocturia. Australas J Ageing 2020;39:9.

13 Cormio L, Cindolo L, Troiano F, et al. Development and Internal validation of novel nomograms based on benign prostatic obstruction-related parameters to predict the risk of prostate cancer at first prostate biopsy. Front Oncol 2018;8:438. https://doi.org/10.3389/fonc.2018.00438

14 Falagario U, Selvaggio O, Carrieri G, et al. Prostatic inflammation is associated with benign prostatic hyperplasia rather than prostate cancer. Journal of Gerontology and Geriatrics 2018;2018:178-182.

15 Falagario UG, Sanguedolce, Stallone G, et al. Elderly patients and prostate biopsy. How old is too old? Journal of Gerontology and Geriatrics 2018;66:163-167.

16 Cockett ATK. The International Consultation on Benign Prostatic Hyperplasia, 1991: Paris, France: World Health Organization. (https://apps.who.int/iris/handle/10665/41818 Accessed on: 2/12/2021).

17 Barry MJ, Fowler FJ Jr, O'Leary MP et al. Correlation of the American Urological Association symptom index with self-administered versions of the Madsen-Iversen, Boyarsky and Maine Medical Assessment Program symptom indexes. Measurement Committee of the American Urological Association. J Urol 1992;148:1558-1563.

18 Morse JM. Prevention Patient Falls, $2^{\text {nd }}$ edn. Sage, Thousand Oaks, CA 1997.

19 Panel on Fall prevention in Older Persons, American Geriatrics Society and British Geriatrics Society. Summary of the Updated American Geriatrics Society/ British Geriatrics Society Clinical Practice Guideline for Prevention of Falls in Older Persons. J Am Geriatr Soc 2011;59:148-157.

20 Savaş Ş, Şehri A, Sacide Nur SC. A study whıch ınvestıgates the relatıonshıp of age, trunk strength, and balance parameters with fall risk. Türk Geriatri Derg 2016;19:174-182

21 Rubenstein $\mathbf{Z}$. Falls in older people: epidemiology, risk factors and strategies for prevention. Age Ageing 2006;35(Suppl 2):ii37-41.

22 Sibley KM, Voth J, Munce SE, et al. Chronic disease and falls in community-dwelling Canadians over 65 years old: a population-based study exploring associations with number and pattern of chronic conditions. BMC Geriatr 2014;14:22.

23 Yoshita P, Patricia WS, Ratliff SM. Chronic health conditions as a risk factor for falls among the community-dwelling US older adults: a zero-Inflated regression modeling approach. Biomed Res Int 2017;2017:5146378. https://doi. org/10.1155/2017/5146378

24 Tsai YJ, Yang PY, Yang YC, et al. Prevalence and risk factors of falls among community-dwelling older people: results from three consecutive waves of the national health interview survey in Taiwan. BMC Geriatrics 2020;20.

25 Gribbin J, Hubbard R, Gladman JR, et al. Risk of falls associated with antihypertensive medication: populationbased case-control study. Age Ageing 2010;39:592-597.
26 Goldstein DS, Pechnik S, Holmes C, et al. Association between supine hypertension and orthostatic hypotension in autonomic failure. Hypertension 2003;42:136-142.

27 Gangavati A, Hajjar I, Quach L, et al. Hypertension, orthostatic hypotension, and the risk of falls in a communitydwelling elderly population: the maintenance of balance, independent living, intellect, and zest in the elderly of Boston study. J Am Geriatr Soc 2011;59:383-389.

28 Fastbom J, Schmidt I. Indikatorer för god läkemedelsterapi hos äldre. In The Swedish National Board for Health and Welfare 2010, In Swedish (http://www.socialstyrelsen.se/ publikationer2010/2010-6-29 Accessed on:2/14/2021).

29 Krauss MJ, Evanoff B, Hitcho E, et al. A case-control study of patient, medication, and care-related risk factors for inpatient falls. J Gen Intern Med 2005;20:116-122. https:// doi.org/10.1111/j.1525-1497.2005.40171.x

30 Mayne D, Stout NR, Aspray TJ. Diabetes, falls and fractures. Age Ageing 2010;39:522-525.

31 Roig M, Eng JJ, Maclntyre DL, et al. Falls in people with chronic obstructive pulmonary disease: an observational cohort study. Respir Med 2011;105:461-469.

32 Beauchamp MK, Hill K, Goldstein RS, et al. Impairments in balance discriminate fallers from non-fallers in COPD. Respir Med 2009;103:1885-1891.

33 Zambon JP, Almeida FG, Conceição RD, et al. Prostatespecific antigen testing in men between 40 and 70 years in Brazil: database from a check-up program. Int braz j urol 2014;40: 745-752.

34 Devore EE, Townsend MK, Resnick NM, et al. The epidemiology of urinary incontinence in women with type 2 diabetes. J Urol 2012;188:1816-1821.

35 Favilla V, Cimino S, Castelli T, et al. Relationship between lower urinary tract symptoms and serum levels of sex hormones in men with symptomatic benign prostatic hyperplasia. BJU Int 2010;106:1700-1703.

36 Tsukamoto T, Masumori N, Rahman M, et al. Change in International Prostate Symptom Score, prostrate-specific antigen and prostate volume in patients with benign prostatic hyperplasia followed longitudinally. Int J Urol 2007;14:321 324. https://doi.org/10.1111/j.1442-2042.2007.01596.x

37 Park DS, Oh JJ, Hong JY, et al. Serum prostate-specific antigen as a predictor of prostate volume and lower urinary tract symptoms in a community-based cohort: a large-scale Korean screening study. Asian J Androl 2013;15:249-253.

38 Tromp AM, Pluijm SM, Smit JH, et al. Fall-risk screening test: a prospective study on predictors for falls in community-dwelling elderly. J Clin Epidemiol 2001;54:837-844

39 Stewart RB, Moore MT, May FE, et al. Nocturia: a risk factor for falls in the elderly. J Am Geriatr Soc 1992;40:1217-1220

40 von Renteln-Kruse W, Krause T. Fall events in geriatric hospital in-patients. Results of prospective recording over a 3 year period. Z Gerontol Geriatr 2004;37:9-14.

41 Frost M, Abrahamsen B, Masud T, et al. Risk factors for fracture in elderly men: a population-based prospective study. Osteoporos Int 2012;23:521-531. 
42 Parsons JK, Mougey J, Lambert L, et al. Lower urinary tract symptoms increase the risk of falls in older men. BJU Int 2009;104:63-68.

43 Chiarelli PE, Mackenzie LA, Osmotherly PG. Urinary incontinence is associated with an increas e in falls: a systematic review. Aust J Physiother 2009;55:89-95
44 Mancini V, Balzarro M, Illiano E, et al. Lower urinary tract symptoms in elderly men: a simple yet comprehensive approach. Journal of Gerontology and Geriatrics 2018;66:245-252. 